\title{
Research on the Narrative Expression of Space Design in Experience Economy Era
}

\author{
Wang Yunlong \\ School of Design, Jianghan University, No. 8 Sanjiaohu Road, \\ Wuhan Economic \& Technological Development Zone, Wuhan, Hubei, P.R. China
}

233348877@qq.com

Keywords: Narrative Expression, Space Design, Experience Economy Era

\begin{abstract}
With the advent of the experience economy era, great material wealth, the traditional space design has been unable to meet the growing demands. Narrative expression space designed as a space to create a post-modern thinking, from the theoretical framework of narrative literature in the field of research and to shape the space, focusing on the significance of space urban landscape, historical and cultural connotation mining space, trying to attract users in the city spaces do and see, think and remember, moved and resonance, let us have a poetic and amusing urban space characteristics.
\end{abstract}

\section{Introduction}

Date of birth, we are in with their own hands, with their facial features, with his body experiencing around the world, like works of art only to be understood in order to reflect the value of life, the environment only in person after the experience can be built. Need to experience life, modern society, under a variety of high-tech instruments and equipment to make many of our behavior becomes programmed in a variety of instruments, products emphasize the "user experience", while in human sensory nerves degenerate, because lost the smell, temperature, humidity, airflow, tactile perception and experience, the psychological feeling are degraded because of the lack of social emotional space, communication space, living space we gradually lost the feeling, sensitive to the feelings of the experience .

Modern Movement architecture Bauhaus brought us, brought a free plane, bringing open space, bringing the steel structure, bringing transparent glass facade, the building brought industrial production . With more and more flat Earth, architectural style yen internationalization. Whether in Shanghai, Tokyo, New York or Paris, people see is the same skyscrapers, shining like cold steel member, as the difference between glass walls reflecting differing only in the color of the sky, you can see even imitate classic predecessors the building appears in the built environment is completely different from the original place. So rely on industrialization technology and the rapid spread of stateless architecture around the world to spread, make people praise the efficiency of praise technology, praise the beauty industry the same time, they lost their integration with the local environment and history of the takeover, more importantly, allowing users to get lost in the emotional resonance key eleven user experience. Traditional architecture in order to reflect some kind of "external truth", to the contemporary building has been reflected over the sustenance of social meaning, reaction technology, reflecting the history and culture, and even became the architect of personal skills field trials, these are associated with a specific "person" has nothing to do with the specific person's experience, life experience has nothing to do, and therefore cannot get people's emotions.

\section{The Proposal and Development of the Experience Economy}

Experience Economy Theory in 1998, as defined by economists, and the "experience economy" The concept is considered by the US consulting firm Strategic Horizons B • Joseph • Pine II and James Gilmore jointly launched $\bullet \mathrm{H} \cdot$ while experiencing the basic theoretical framework is constructed out of the economy for the first time. A jointly published by Pine and Gilmore in the United States, 
"Harvard Business Review" magazine's "experience economy era coming" (Welcome to The Experience Economy) paper, so the sensation of the economic sector researchers and practitioners . In 1999, the Harvard Business School Press book "experience economy", is the meaning of the experience economy is discussed more specific and systematic. Thereafter, in 2001, Professor Bernd Schmitt • H • Columbia University has published the "experiential marketing" this book.

Experience Economy is a new type of economic following the agricultural economy, industrial economy, service economy emerged. Experience Economy and other types of completely different, just to pursue their own other types of value can be achieved, while the economy is based on the experience changed the consumer as the core business model, from commodity sales for the purpose of phase transition to meet consumer psychology demand and induce phase consumer behavior. Commercial center as the carrier, to provide experience and exchange place, mobilize consumer behavior from the emotion, so that consumers become self-satisfied demand leader.

First, the experience economy is to meet the individual needs of consumers as the starting point. In the experience economy era, the first thing to consider is the business operations to meet the individual needs of consumers, and commercial space design must take into account the experience of the consumer, in a limited space for consumers to create unlimited imagination. Secondly, the coming of experience economy gives consumers customized services, customized service and this wonderful experience to bring consumers experiences and memories, enabling consumers to experience the process of generating a positive response. During the experience the business environment, the consumers place brings good feelings will not only enjoy themselves, and take that experience and feelings with others to share. Positive evaluation of the business center will be spread among consumers to family and colleagues, to attract more consumers had come here, to participate in the experience of the business atmosphere, to promote the appeal and influence of commercial buildings, resulting in "experience" effect. Secondly, the experience economy era of commercial buildings that provide consumers with public life and popular culture of leisure, communication, experience the place as a precondition to the consumer as the core, consumer psychological needs and shopping experience as the starting point to play commercial buildings stage experience space effect, so that consumers in the shopping process to experience the taste of happiness and satisfaction.

Experience Economy has changed the lifestyles and consumption patterns of consumers, to make business run more open, healthy and energetic. Since the social economy from a market economy to the experience economy era, the commercial buildings designed to conform to the experience of economic development, the purpose of the business model into the experience of the business model, the traditional commercial space form into the experience of the topic space, so as to enable the development of commercial buildings conform to the trend of the times. From the consumer as the core to meet the needs of individual consumers, the commercial space humanized design considerations; from consumer consumption patterns and changes in consumption patterns, commercial space for the consumer to create a satisfactory stage; from consumers Being constantly meet, memories last forever, commercial space environment experience, we can say, the experience economy to make commercial buildings from traditional to innovation, so that consumers into one, feel the experience commercial space brings them satisfaction and comfort.

\section{Theory of Narrative Expression of Spatial Design}

The Latin etymology of narrative is "about" and "know" means. "Narrative is a means of communication, forms of knowledge and understanding patterns, self and the world, self-mediation between the others, is a way to create order and meaning for human discrete experience." This approach is not limited to language in the traditional sense, but rather refers to all carriers can convey information. "From the three elements of the narrative: the narrator, the media, the recipient, the narrative may be in other forms of non-verbal vector art exists, such as film, sculpture, painting and architecture, etc., instead of using performance as a text or oral presentation out of the story. "Since the premise of the narrative is to convey the relationship between media and the recipient of 
the narrative, so if the space were designed by designer narrative, people's behavior induced to establish a close relationship with the space, this space will become a carrier It was given the intrinsic value may narrative.

Fundamentally, "all discourse is narrative," the narrative is one of the basic ways humans communicate information, but also one of the basic ways people interpret the outside world. Narrative Space is a new concept in recent years on the basis of theories and methods of research on evolving. It is the narrator to the material elements of the space as a narrative medium, use of relevant means of expression and signified, etc., expressing the spirit of place to the recipient, causing the recipient of a series of spiritual experience. At the same time, there is a different narrative media recipients based on personal knowledge and awareness may in turn generate self-interpretation of space in the interpretation process.

In the field of space design, narrative research is largely associated with the rise of postmodern theory, in particular the development of architectural design theory. It should be said, is to design narrative design objects as a medium of ideographic support and contact with the outside boundary of the human heart, people to form self-interpretation of the physical environment through the design objects experience.

\section{The Evaluation of Space Design Narrative Expression}

The concept includes a narrative content and narrative approach in two ways. Narrative structure is built on the timeline space varied combinations of temporal relations. This combination of spatial and temporal relationship to the space environment is seen as a carrier with the encoded information, the movement of people in space based on their emotional experience of the space environment in the process of decoding. Narrative structure narrative space evaluation is to clear space location has the possibility of narrative.

The "Strength" Intentionality of Space. "Strength" of intent is to focus on the information carried by the space environment, as well as the expression of the way of information. That is through the use of symbols, color, orientation, scale, etc. metaphor, evoked the experience of those associations. In the space of sequence organization tends to convey a clear design intent choreographed by flow lines. Such as the Forbidden City in Beijing spatial sequence is a "strong" design intent. Such a space has a strong imagery and integrity.

"Weak" intentionality narrative space, expressed concern at the "mood." That's according to their own experiences and emotional experience of self-made interpretations. It is no obvious sign of the appearance, but concerns overlap with different viewpoints and ambiguous visual images, relying on their own experience of those who experience a series of these pictures give a new interpretation.

The Story of Space Theme. Whether it is "strong" intentionality space, or "weak" intentionality space, space theme is the expression of space has a narrative foundation. As already mentioned, the narrative theme in different background is divided into "unified" and "diversity" theme, but regardless of the "unification" or "diversity", is centered on a particular event or a multi-dimensional plot expand. Here the "episode" is beyond the purely functional and aesthetic ideographic, non-homogenized spirit of place. In the narrative design, the plot is the "story." "By way of storytelling expansion of urban space design, it is a post-modern urban design to build thinking." Narrative design theme is based on the story of the space environment capable of carrying people on the basis of collective memory, through storytelling the way the spatial form and cultural relevance, geographical features Blending, enhance people's sense of identity space place, the relationship between people and the urban environment more intimate. For example, the 2010 Shanghai World Expo theme of "Better City, Better Life" is a story to illustrate the tone of the relationship between the city and the people, the city and the environment.

Narrative structure narrative space evaluation of the "story of the subject" is the most critical factor in the overall evaluation. On the one hand it is a prerequisite premise narrative design, on the other hand is an important method of narrative design. Specifically, not all accommodation spaces have a clear theme, but the theme has space to make a place with the nature of the narrative. Design narrative sequence of space required by the story unfold gradually progressive and layers. 
The Specialization of Design Approach. Adaptability of narrative logic and method in urban open space design, the reference film montage theory, the temporal montage of clips and decomposition and recombination as a narrative design operating practices, and were constructed of thinking and expression from two aspects are described. Traditional urban design, classification and evaluation methods for the design have a more mature system, any design on three-dimensional space also follow this standard. The Narrative Space Narrative Structure Evaluation studied in this paper for the design of the evaluation method, and more focused on the cognitive narrative space property is built on a "narrative" on the basis of four-dimensional space. It emphasizes the interaction between time and space, focusing on the four-dimensional space to evoke the soul and get the reaction varied spiritual experience. Thus, its design method is based on the time and induction.

\section{Conclusion}

Open Space narrative design is by one or several themes and have the story logic of creative choreography will be a lot of space has inherent logic and sense of order and through a series of cultural symbols and narrative Research and application of spatial patterns of behavior, build a place meaning and emotional experience of urban open space. This design approach is based on spatial narrative theory, the urban space as a kind of emotional support and communication ideographic people's hearts with the external environment of the media, focusing on urban expression of regional culture and people's spiritual needs. Narrative design method is to address the core space and narrative theory Narrative adaptive design methods in urban open space design practicality in space design.

\section{References}

[1] Huifang Zhou: Jiangxi Social Sciences, Vol. 6 (2014) No 53, p.25-26

[2] Hongli Zhang: Urban Studies, Vol. 12 (2015) No 27, p.74-76

[3] Qin Guo: International Urban Planning, Vol. 1 (2012) No 33, p.11-14

[4] Jieming Liu: South Architecture, Vol. 3 (2010) No33, p.121-124

[5] Zhang Liang: City Building, Vol. 3 (2011) No33, p.121-124 